\title{
SOBRE AUTOTRADUCCIÓN Y PARATEXTO EN BOQUITAS PINTADAS. FOLLETÍN DE MANUEL PUIG
}

\author{
ABOUT SELF-TRANSLATION AND PARATEXT IN BOQUITAS PINTADAS. \\ FOLLETÍN BY MANUEL PUIG
}

\author{
SOBRE AUTOTRADUÇÃO E PARATEXTOS EM BOQUITAS PINTADAS. \\ FOLLETÍN DE MANUEL PUIG
}

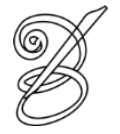 \\ Giselle RODAS ${ }^{1}$ \\ Universidad de Lomas de Zamora, Argentina \\ Universidad del Cine, Argentina
}

\begin{abstract}
Resumen: La injerencia de Manuel Puig en el campo de la traducción puede estudiarse en un caso ejemplar como el de su novela Boquitas pintadas. Folletín (1969). El autor colaboró activamente en la traducción de las versiones realizadas especialmente para Italia, donde la novela apareció como Una frase, un rigo appena. Romanzo d'appendice (1971); para Francia, donde se tituló Le plus beau tango du monde (1972), y para Estados Unidos, donde se publicó como Heartbreak Tango. A Serial (1973). Su intervención se concentró fundamentalmente en lo que se refiere a los elementos paratextuales. Títulos, subtítulos y epígrafes que encabezan cada capítulo fueron especialmente adaptados en función de los nuevos espacios de recepción literarios y culturales en que la obra circularía. Este artículo estudia el rol de Manuel Puig como traductor a través del análisis de las traducciones mencionadas. Para ello se tienen en cuenta tanto las versiones publicadas como algunas huellas del proceso de escritura legibles en los borradores de trabajo del archivo personal del escritor. Cabe destacar que lo que todas estas traducciones priorizan y conservan de distintos modos es especialmente el dominio del tango como elemento peculiar de la cultura de partida, entre otros materiales representativos de la cultura popular.
\end{abstract}

Palabras clave: Manuel Puig. Boquitas pintadas. Autotraducción. Paratexto. Reescrituras.

Abstract: The interference of Manuel Puig in the field of translation can be studied in an exemplary case such as his novel Boquitas pintadas. Folletin (1969). The author actively collaborated in the translation of the versions made especially for Italy, where the novel appeared as Una frase, un rigo appen a. Romanzo d'appendice (1971), for France, where it was titled Le plus beau tango du monde (1972), and for the United States, where it was published as Heartbreak Tango. A Serial (1973). His intervention focused mainly on the paratextual elements. Titles, subtitles and epigraphs that head each chapter were specially adapted in function of the new spaces of literary and cultural reception in which the work would circulate. This article focuses on the role of Manuel Puig as a translator in the analysis of the mentioned translations. For this, we consider the published versions and some traces of the writing process readable in the working drafts of the personal file of the writer. It should be noted that what all these translations prioritize and conserve in different ways is especially the tango as a peculiar element of the culture of departure, among other materials representative of popular culture.

Key words: Manuel Puig. Boquitas pintadas. Self-Translation. Paratext. Rewriting.

Resumo: A interferência de Manuel Puig no campo da tradução pode ser estudada num caso exemplar como o de seu romance Boquitas pintadas. Folletín (1969). O autor colaborou ativamente com a tradução das versões realizadas especialmente para Itália, onde o romance apareceu como Una frase, un rigo appena. Romanzo d'appendice (1971), para a França, com o título Le plus beau tango du monde (1972), e para os Estados Unidos, publicado como Heartbreak Tango. A Serial (1973). Sua intervenção focalizou fundamentalmente em aspectos referentes a elementos paratextuais. Títulos, subtítulos e epígrafes que iniciam cada capítulo foram especialmente adaptados em função dos novos espaços de recepção literários e culturais nos quais a obra circularia. Este artigo 
se centra na função de Manuel Puig como tradutor na análise das traduções mencionadas. Deste modo, se considera tanto as versões publicadas, como algumas marcas do processo de escrita legíveis nos rascunhos de trabalho do arquivo pessoal do escritor. Deve-se notar que o que todas estas traduções priorizam e conservam de diferentes maneiras é especialmente o tango como um elemento peculiar da cultura de partida, entre outros materiais representativos da cultura popular.

Palavras-chave: Manuel Puig. Boquitas pintadas. Autotradução. Paratexto. Re-escritura.

RECEBIDO EM: 5 de julho de 2018

ACEITO EM: 10 de outubro de 2018

PUBLICADO EM: abril 2019 


\section{Introducción}

La novela de Manuel Puig, Boquitas pintadas. Folletín, publicada por la casa editorial Sudamericana de Buenos Aires en 1969, avivó un interés generalizado apenas fue puesta en circulación y se convirtió en un best seller que motivó inmediatas traducciones. Su autor colaboró activamente de la traslación a las nuevas lenguas en las que la obra sería traspuesta, especialmente en aquellos casos en los que dominaba los idiomas de destino, como el francés, el italiano o el inglés y aunque no realizó traducciones íntegras, se encargó de adaptar los elementos paratextuales, aspecto central en la semántica de esta obra. Este artículo, producto de una investigación más amplia (RODAS, 2015), propone estudiar algunas cuestiones de autotraducción (GRUTMAN, 2009a; RECUENCO PEÑALVER, 2011), es decir, del trabajo de traducción a otra lengua que hace el mismo autor sobre su propia obra, en el caso del escritor Manuel Puig y su intervención sobre Boquitas pintadas. Folletín.

Sobre los elementos paratextuales, Gerard Genette (2001) ha señalado que deben pensarse como un umbral, una vía de acceso al texto. En sus intervenciones sobre esta zona, Puig trató de privilegiar el contacto con el universo enciclopédico y sociocultural del lector. Ciertas transformaciones realizadas sobre algunos elementos paratextuales de las primeras traducciones de esta novela publicadas en Italia (1971), Francia (1972) y Estados Unidos (1973) representan casos paradigmáticos de esta operatoria legibles en numerosos testimonios autógrafos conservados en el archivo personal del escritor. ${ }^{2}$ Según nuestra hipótesis, el paratexto de Boquitas pintadas. Folletín, zona adaptada en las traducciones y visible principalmente en títulos, subtítulos y epígrafes, pone al descubierto las diferencias culturales y la definición de un público potencialmente distinto al que se pretende captar. El desempeño de Puig como colaborador en este campo entra además en coherencia con sus prácticas generales de trabajo: escribir, corregir, reescribir y releer meticulosamente un plan razonado, como ha sido demostrado en la definición de su poética escritural a través del análisis geneticista de esta misma novela (RODAS, 2015), y también permite extraer conclusiones sobre la relación entre este ejercicio y el desarrollo de su proyecto autoral más allá de la obra que analizamos.

Nos proponemos entonces cotejar los elementos paratextuales de la primera edición de Boquitas pintadas. Folletín publicada en la República Argentina con las traducciones mencionadas para leer la intervención de Puig en el campo de la autotraducción y su compromiso por ceñir vínculos entre la obra y otros espacios de circulación posibles. Este trabajo contará con las siguientes secciones: unas palabras introductorias dedicadas a la cuestión 
del paratexto en el texto fuente y la autotraducción en Manuel Puig, luego un análisis sobre las traducciones para Italia, Francia y Estados Unidos ${ }^{3}$ y, por último, un cotejo de las versiones estudiadas con la finalidad de extraer conclusiones sobre el rol de Manuel Puig como autotraductor del paratexto de su novela. ${ }^{4}$

\section{Paratextualidad y autotraducción en Boquitas pintadas. Folletín}

La obra que estudiamos extrae su título del foxtrot "Rubias de New York" (1934), escrito por Alfredo Le Pera y cantado por Carlos Gardel en la película El tango en Broadway (1934). Puig extrajo otras citas de esa canción para los epígrafes del tercer capítulo ("Deliciosas criaturas perfumadas / quiero el beso de sus boquitas pintadas"), del quinto ("Dan envidia a las estrellas / yo no sé vivir sin ellas"), y para los intertítulos de la primera y de la segunda parte en que se divide la obra: "Boquitas pintadas de rojo carmesí" y "Boquitas azules, violáceas, negras". No está de más adelantar que Puig se sirve de otras doce citas de tangos escritos por Le Pera y musicalizados por Carlos Gardel, canciones que había interpretado en películas grabadas en el exterior durante el período 1932-1935, momento de gran fama internacional al que Le Pera

74 contribuyó considerablemente. ${ }^{5}$ También introduce una frase de un tango de Luis Rubistein, “Charlemos” (1940), y una del único bolero citado como epígrafe en el capítulo quince, “Azul” de Agustín Lara. Para adelantar, y tal como se verá luego, este ejercicio de Puig con los recursos que le brinda la cultura popular es aprovechado en esta novela, así como también en el resto de su producción, como un signo de su poética autoral.

En Umbrales (2001), donde estudia los paratextos, Genette advierte que el destinatario del título no es sólo el lector, sino el público en general, categoría que abarca a aquellos que no leen necesariamente el texto pero participan de su difusión: "Porque si el texto es un objeto de lectura, el título, como el nombre del autor, es un objeto de circulación” (2001, p. 68). Cuando Puig elige el título para su novela, extrae una referencia que le es familiar al público y asegura una circulación efectiva, no sólo porque se trata de un fragmento que canta Gardel sino porque además lo hace en una escena memorable, donde entona la canción más representativa del filme.

Los epígrafes de la novela establecen otras significaciones complementarias. Dice Genette: "definiré grosso modo el epígrafe como una cita ubicada en exergo, generalmente al frente de la obra o de parte de la obra: 'en exergo' significa literalmente fuera de la obra, pero quizás aquí el exergo es un borde de la obra, generalmente cerca del texto [...]” (2001, p. 123). Es justamente en ese espacio de borde donde consideramos los epígrafes de esta novela en función del objetivo de este trabajo, ya que allí se establece una sutil frontera entre el adentro y 
el afuera del texto que lo pone en contacto directo con los distintos espacios de circulación, como se verá a lo largo del análisis. Además, si el epígrafe es un signo que se quiere índice de algún tipo de cultura, el juego con el afuera del texto apela a la memoria y al conocimiento de la cultura de masas, del tango, del foxtrot, del bolero o de las películas implicadas, ejercicio literario de apropiación y reapropiación de los materiales de la cultura popular practicado con recurrencia en la poética de este autor, como se adelantaba anteriormente. Es entonces que cada una de las citas musicaliza las entregas con un movimiento rítmico: cómo no entonar aquellas que se reconocen, cómo no ambientarlas y seguir su lectura con el tono acorde que coloca en un nivel semejante las enciclopedias de la producción y de la recepción. Asimismo, como entiende María Laura Spoturno (2014), en la dimensión paratextual reside gran parte del potencial pragmático, ya que "en muchas ocasiones las instrucciones de lectura conferidas en estos espacios del texto tienen como objetivo introducir o reponer cuestiones culturales que serían, de otro modo, inaccesibles para el lector de la obra o de la traducción" (SPOTURNO, 2014, p. 67). Esto permite el reconocimiento y difusión de ciertos elementos claves de la cultura de partida, pero al mismo tiempo, al ser adaptados en función de la cultura receptora y en ocasiones mezclarse con materiales propios de ésta, se acomodan en un movimiento doble de inserción y transmisión de elementos nuevos y foráneos; y de reconocimiento y reapropiación de tradiciones culturales propias.

Como lo hemos adelantado, Puig interviene muy particularmente en las zonas paratextuales de las versiones para Italia, Francia y Estados Unidos, al punto que en una entrevista con la escritora Elena Poniatowska declara:

Con Boquitas Pintadas sobre todo hablo de adaptación. Había muchos localismos y el problema fundamental de las letras de las canciones-tangos y boleros (archiconocidos en Latinoamérica y España) influía sobre el lenguaje de los personajes. Eso hubo que sugerirlo de algún modo por medio de canciones equivalentes [...] Los títulos de la novela tuvieron que seguir a los cambios de canciones y así fue que en Italia Boquitas Pintadas se llamó Una frase, un rigo appena, en Francia Le plus beau tango du monde y en Estados Unidos Heartbreak tango (PONIATOWSKA, 1974, p. 20).

Esta declaración lleva a pensar en el sentido de la autotraducción, tarea que vincula a Puig con otros escritores ligados a esta práctica, ${ }^{6}$ y en el contexto del caso que planteamos interesa pensar algunas posiciones teóricas acordes como la de María Carmen Molina Romero (2003) quien concibe el fenómeno como un punto intermedio entre la traducción y una nueva versión que el autor está habilitado para adaptar: "El escritor posee la libertad de escaparse traduciendo, de 
(re)crear de nuevo el texto" (2003), aspecto en común con el caso que analizamos. También Blake Hanna (1972) sostiene que la autotraducción no se subordina a la versión original y que tanto el texto fuente como su traducción deben considerarse manifestaciones idénticas del pensamiento del autor, lo que refuerza la idea de que habría dos versiones de la misma obra y admite considerar los textos que analizamos como (re)creaciones. La perspectiva de Brian Fitch (1983) valora al autotraductor como escritor en quien predomina lo creativo e introduce nuevos elementos inexistentes en la primera versión, punto acorde al escritor que estudiamos quien, como veremos, se sirve con libertad de todos los recursos disponibles para (re)crear y modificar el texto de origen. Por su parte, Valentina Mercuri (2009) y Ovidio Carbonell Cortés (1997) consideran al autotraductor como un mediador cultural, "un nexo que permite la comunicación entre dos comunidades que no comparten el mismo sistema lingüístico" (MERCURI, 2009, p. 136), y que ajusta su interpretación del texto de acuerdo con las expectativas del contexto de recepción, planteo teórico que también se ajusta a los objetivos de nuestra hipótesis y que analizaremos a continuación.

\section{La traducción para Italia (1971)}

Una frase, un rigo appena. Romanzo d'appendice (1971) es el título de la traducción al italiano que estuvo a cargo del prestigioso Enrico Cicogna, ${ }^{7}$ quien ya había traducido la novela más representativa del boom de la literatura latinoamericana, Cien años de soledad (Cento anni di solitudine, 1968). La frase para el título en italiano corresponde a un verso del tango Scrivimi ${ }^{8}$ que fue interpretado por el popular cantante Carlo Buti. La letra inspiró los intertítulos de la primera y de la segunda parte: "Una frase scritta con elegante calligrafia" y "Un rigo sbiadito, scarabocchiato, cancellato”. Si bien en un principio Puig había traducido casi literalmente al italiano los intertítulos de la edición argentina de Boquitas pintadas. Folletín, como puede corroborarse en sus borradores, ${ }^{9}$ finalmente los suprime y selecciona la canción más representativa del espacio en que habrá de circular la obra eliminando a "Rubias de New York", de tono ágil y festivo, como intertexto clave, y transformando a Scrivimi, más nostálgico y afligido, como soporte del diálogo entre el texto y sus nuevos lectores. También vale señalar que en esta versión el subtítulo "Folletín", género que la novela respeta y a la vez transgrede (RODAS, 2015), es traducido por su equivalente Romanzo d'appendice, forma literaria de extensa trayectoria en Italia, ${ }^{10}$ mencionada en la contratapa del libro, donde se indica que Puig no se atiene estrictamente a las normas del género: "maneggia con disinvoltura le sciroppose convenzioni del romanzo d'appendice ma col fermo proposito di non restarne prigioniero." 
La versión para Italia fue rigurosamente intervenida por el autor. Puig seleccionó largos fragmentos para los epígrafes de tangos, que en principio tradujo al italiano. Los documentos de su archivo N.B.89.1095-1190, conjunto de mecanogramas con correcciones manuscritas, son de los primeros testimonios que dan cuenta de dichos movimientos. Allí se conservan largos segmentos de nuevos tangos traducidos al italiano que incluyen canciones de letristas que no estaban presentes en el texto fuente, entre ellos, Homero Manzi, Antonio Miguel Podestá y Manuel Romero. En las reescrituras, Puig busca la traducción más afín al universo de recepción. Un ejemplo es el trabajo que realiza sobre un extenso fragmento del tango "Charlemos" (Luis Rubistein, 1940), del cual se conservan dos etapas de borradores (N.B.89.1103 y N.B.89.1100), donde introduce numerosas transformaciones centradas, principalmente, en la sustitución de conceptos. Un caso particular es el de la frase "no corte" que aparece en el tango, referida a la solicitud que hace el enunciador para evitar que su receptora cuelgue el teléfono. ${ }^{11}$ En la primera lección (N.B.89.1103), el traductor elige la forma "non stacchi”, frase de uso poco común para el contexto de una comunicación telefónica. En una instancia posterior (N.B.89.1100) suprime esa forma y la reemplaza por la expresión de uso más corriente "non riagganci". Asimismo, se permite adaptar más libremente otras fórmulas, por ejemplo, donde el tango dice "sigamos con la ilusión", ${ }^{12}$ la primera lección arroja “non perdiamo l'illusione” (N.B.89.1103), en tanto que en la segunda se reemplaza por “impossibile illusion” (N.B.89.1100).

Posteriormente, una vez revisadas y seleccionadas para cada capítulo, esas letras son transcriptas a mano (N.B.88.1092-1094) y, en ocasiones, adquieren nuevas reescrituras. Todos los fragmentos de epígrafes son extensos, poseen entre seis y diecisiete versos, en comparación con los del texto fuente que oscila entre una y seis líneas. Sin embargo, a pesar de todo este trabajo de traducción, Puig concluyó que los epígrafes para Italia debían permanecer en español. En un artículo publicado en la revista Confirmado, titulado "Papeles son papeles", sin datos de autor, sostiene: "El problema más difícil era que, al traducir, desaparecían las imágenes y los conceptos [...] Los epígrafes fueron reemplazados por estrofas enteras de tangos" (PUIG, 1970, p. 44). Como testimonio, tres folios (N.B.2.0065r, N.B.2.0068r y N.B.2.0070r) presentan esquemáticamente el título o algún verso del tango que irá a cada capítulo en español. Allí, el autor realiza anotaciones metaescriturarias sobre distintos aspectos: el tono que buscará ("algo alegre") o la extensión de la cita (“tratar de alargar"). Otros documentos (N.B.87.1086-1091) presentan extensos fragmentos de tangos en español, algunos de los cuales irán a la versión publicada en Italia. También se conservan papeles (N.B.90.1110-1118) en los que se abrevian 
aquellos largos segmentos y con lápiz negro se señalan los versos seleccionados. La elección final queda nuevamente transcripta en los testimonios N.B.90.1119-1121.

Las citas de la edición italiana incluyen nuevos intertextos. Además de introducir otros tangos de Gardel y Le Pera, que no estaban presentes en la edición argentina, tales como “Amargura" (1934) y "Silencio" (1932), se define la incorporación de versos de Manuel Romero ("Buenos Aires", 1923 y "La muchacha del circo", 1928), Homero Manzi ("Tal vez será su voz”, 1943 y “Malena”, 1941) y Antonio Miguel Podestá (“Como abrazado a un rencor”, 1930). También se incluye un bolero, pero no se trata de "Azul", sino de "Perfidia" (1939) de Alberto Domínguez Borrás. ${ }^{13}$ Sólo una de las citas, correspondiente al tercer capítulo coincide exactamente en su ubicación con respecto a la edición argentina: "Deliciosas criaturas perfumadas / quiero el beso de sus boquitas pintadas" (PUIG, 1969, p. 34). La versión para Italia ajusta su guía para el lector poniendo al interlocutor en contexto ya que al pie de cada epígrafe se aclara el género citado (tango, fox-trot o bolero) y el título de la canción aludida, en contraposición con el texto fuente que sólo indica al letrista.

Conservar como en este caso parte del aparato paratextual en el idioma del texto de origen debe interpretarse como un acto decisivo por respetar el espíritu y el aire poético de las citas. De lo precedente queda claro también que la traducción al italiano de los tangos para los epígrafes no convence al escritor. Opta entonces por reproducir frases extensas que den imágenes más claras y acabadas, del mismo modo que lo hará en 1972 para la edición en español de la casa catalana Seix Barral (RODAS, 2010). Esta solución facilita la interpretación del lector al introducir referencias que no sólo evocan una melodía, sino que expresan una idea más completa o un contenido pleno de imágenes. Para ejemplificar, reproducimos el caso de la cita del capítulo doce en el texto fuente y en la versión en italiano:

\begin{tabular}{|c|l|}
\hline $\begin{array}{c}\text { Boquitas pintadas. Folletín } \\
\text { (Sudamericana, 1969) } \\
\text { (Duodécima entrega) }\end{array}$ & $\begin{array}{c}\text { Una frase, un rigo appena. Romanzo d'appendice } \\
\text { (Feltrinelli, 1971) } \\
\text { (Dodicesima puntata) }\end{array}$ \\
\hline “...fue el centinela de mi promesa de amor...” & $\begin{array}{l}\text { Nada le debo a la vida, } \\
\text { nada le debo al amor... } \\
\text { yo quiero morir conmigo, } \\
\text { sin confesión y sin Dios, } \\
\text { crucificado a mis penas } \\
\text { como abrazado a un rencor } \\
(\text { dal tango "Como abrazado a un rencor") }\end{array}$ \\
\hline
\end{tabular}

Por otro lado, la presencia del tango en el título y en los epígrafes puede leerse como una forma de captar al lector italiano a través de un elemento con el que se suele vincular a la 
cultura argentina, lo cual podría relacionarse con la idea de que el paratexto "tiende un puente intercultural que abrevia la distancia que hay con el otro, posiblemente representado también en la imagen de lector instituido en el texto" (SPOTURNO, 2011, p. 152). Esto puede verse también en la cubierta del libro, debajo del título, donde se presenta una frase que incluye su referencia: "Una love story degli Anni Trenta: amore folli malattia tanghi genialitá ironia". Asimismo, en la contratapa, la síntesis argumental inicia: "Ogni capitolo di questo romanzo d'appendice argentino, che ci giunge accreditato da clamorosi successi, è preceduto da un brano ripreso da un tango che ne mette in risalto gli ingredienti drammatico-sentimentali". Como se ha visto, Puig no desconoce ni desatiende las dificultades que el público italiano puede tener para comprender el lenguaje del tango, sino que reelabora el paratexto con el objeto de hacerlo comprensible y para ello adopta todas las libertades posibles.

\section{La traducción para Francia (1972)}

En Francia, la novela traducida por Laure Guille-Bataillon ${ }^{14}$ se titula Le plus beau tango du monde, ${ }^{15}$ una chanson de René Sarvil de contenido nostálgico que pretende un nuevo diálogo con sus interlocutores. La misma fuente proporciona los versos para el epígrafe de la decimotercera entrega: «Son souvenir me poursuit jour et nuit / et toujours je ne pense qu'à lui / car il m'a fait connaître l'amour / pour tou-jours» (1972a, p. 202). De allí, también se extrae el intertítulo de la primera parte: «Le plus beau des tous les tangos du monde / C'est celui que

j'ai dansé dans vos bras», y con algunas transformaciones el de la segunda, «J'ai dansé d'autres tangos à la ronde, / mais aucun n'égalera celui-là». ${ }^{16}$ Es notable la repetición del vocablo tango que aparece en las frases citadas. En una reseña sobre la novela, Albert Bensoussan apunta: «Le titre français, imaginé avec bonheur par sa traductrice, nous entraîne dans les effluves entêtants de l'âme argentine: le tango» (1972, p. 102). Al igual que en la versión italiana, la novela traducida encuentra un modo de intensificar su enlace con el texto fuente y con su contexto de producción original a través de la referencia iterativa de un concepto representativo de la cultura de partida que podría funcionar para captar el interés de potenciales lectores en la cultura de destino. No obstante, para esta versión se eligieron otras canciones en lengua francesa como fuente de los epígrafes. Esto ocurre, por ejemplo, con Il pleut sur la route (Robert Chamfleury / Henry Himmel, 1935), Adieu Paris (Berthe Sylva, 1930), J'ai pleuré sur tes pas (Roland Tessier / Jacque Simonot, 1943) y con el único foxtrot citado en el capítulo cuatro, Vous avez l'éclat de la rose (R. Sarvil / V. Scotto, 1935) que forma parte de la opereta Un de la Canebière, al igual que la canción para el título. Otro dato llamativo es que muchas de las 
canciones citadas fueron interpretadas en algún momento de su carrera por el reconocido cantante francés de los años 30, Tino Rossi, ${ }^{17}$ entre ellas, Le plus beau tango du monde, Vous avez l'éclat de la rose, Il pleut sur la route, "Amor, amor, amor", "Bésame mucho" y J'attendrai.

Los epígrafes de esta versión aparecen en francés, a cuyo pie se indica el título de la canción reproducida y el género, bolero, tango o fox-trot. Sobre esta traducción, antes de que se publicara, Puig había declarado palabras similares a las referidas sobre las versiones previas en el artículo titulado "Manuel a casa, Gardel y leer a la Sorbona" (1970), publicado inicialmente en la revista Panorama:

Boquitas empieza con una cita de un tango de Le Pera "Era para mí la vida entera..." Para el lector argentino esas pocas palabras tienen una carga nostálgica muy especial y que funcionan tanto por la letra como por la melodía que evocan. En cambio, en Francia, traducidas, sólo pueden significar una trivialidad [...] Se me ocurrió alargar esos epígrafes, breves en general, o cambiarlos en otros casos. La finalidad era evocar una atmósfera, cierta época, un estado de ánimo. Para el lector europeo, agrego material que le permita impregnarse: en algunos casos una letra de tango completa, y por supuesto que dé bien en traducción, que dé imágenes claras y expresivas (PUIG, 2006 [1970], p. 37).

El tango continúa siendo el género más citado en nueve de un total de dieciséis epígrafes. Además de algunos presentes en las versiones anteriores -como "Melodía de arrabal" (Le Pera / Battistella, 1932), que estaba en el texto fuente, o "Malena" (Homero Manzi / Lucio Demare, 1941) y “Como abrazado a un rencor” (Antonio Miguel Podestá / Rafael Rossi, 1930), en la versión italiana-, se incorporan los de la tradición francesa, por ejemplo, Il pleut sur la route o $J$ 'ai pleuré sur tes pas. También aparecen seis epígrafes que introducen boleros, a diferencia de las ediciones previas en las cuales sólo aparecía uno. Junto con "Perfidia" (1939, Alberto Domínguez Borras), cuya traducción al francés corresponde a la versión cantada por Luis Mariano, ${ }^{18}$ también se leen versos de los boleros “Amor, amor, amor” (Ricardo López Méndez y Gabriel Ruiz Galindo, 1941) ${ }^{19}$ y de J'attendrai (Nino Rastelli / Dino Olivieri, 1933), ${ }^{20}$ ambos en las versiones francesas interpretadas por Tino Rossi.

A pesar de que son escasos los borradores de las traducciones para los epígrafes (N.B.91.1124-1125), los conservados permiten leer algunas cuestiones sobre el proceso seguido en la elección. Entre esos documentos encontramos la transcripción mecanografiada de los boleros "Perfidia", siguiendo la traducción cantada por Luis Mariano, "Bésame mucho", coincidente con la que entona Tino Rossi, y una chanson de la cual no se incluye ningún epígrafe, Les roses blanches (Charles Louis-Pothier / León Raiter, 1925). En los boleros 
transcriptos se encuentran señaladas las frases que se citarán, que son las que encabezan los dos primeros capítulos, extraídos de "Perfidia", y el noveno, de "Bésame mucho".

Solamente dos citas de esta edición coinciden con las que aparecían en el texto fuente. Una de ellas remite al tango "Melodía de arrabal", que se encuentra en la décima entrega de la versión francesa: "tu as l'âme inquiète / d'un moineau sentimental" (PUIG, 1972a, p. 157) y que se reproduce exactamente en el mismo capítulo que la primera edición argentina: "vos ${ }^{21}$ tenés el alma inquieta de un gorrión sentimental" (PUIG, 1969, p. 145). La otra aparece en la decimosexta entrega de la versión francesa y pertenece al tango "Volvió una noche", que en el texto de origen posee un verso menos ("Las horas que pasan ya no vuelven más" [PUIG, 1969, p. 184]): "Tu mens! tu mens! aurais-je voulu dire / les heures qui passent ne reviennent pas" (PUIG, 1972a, p. 261).

Un último punto a destacar sobre la versión para Francia se refiere al subtítulo "Folletín", el cual es totalmente omitido, justamente en el espacio geográfico donde el género se origina y prolifera en una extensa tradición literaria. ${ }^{22}$ En la contratapa se hace una breve mención sobre este tema y se aclara que Puig no hace estrictamente un folletín, sino una reelaboración (Pastiche de roman-feuilleton), tal vez esto se deba al amplio conocimiento que el público tiene del folletín en Francia y de las expectativas con que podría recibirlo.

\section{La traducción para Estados Unidos (1973)}

Heartbreak Tango. A Serial ${ }^{23}$ es el título de la novela traducida por Suzanne Jill Levine, en cuyo trabajo Puig colaboró. Al igual que en la publicación francesa, el aparato paratextual recalca la presencia del tango como elemento representativo de la cultura fuente. "A tango lingers on true red lips" es el intertítulo de la primera parte y "A Tango lingers on blue, violet, black lips", el de la segunda. De la traducción de "Maldito tango" de Luis Roldán (1916), titulado Blame that tango, Puig y la traductora extraen la frase Heartbreak Tango:

Boquitas pintadas, a pesar de ser un título cursi, despierta cierta nostalgia en el lector. Hearthbreak Tango es otra frase cursi que también hace alusión a los corazones rotos, subrayando la presencia del tango en la novela original (JILL LEVINE, 1998, p. 170).

Esa canción es una de las que entona el personaje de Rabadilla en el capítulo once cuando comienza a presentir la traición de Pancho, padre de su hijo. En esta versión en particular también será evocada como epígrafe de la cuarta entrega ("My obsession, heartbreak tango, / plunged my soul to deepest sin, / as the music of that tango / set my poor heart all a-spin [1973a, 
p. 45]) y de la novena (I will always blame that tango / and the wooer with his wiles, / once he'd made my heart break / all he told me was good-by" [1973a, p. 115]).

En cuanto a los epígrafes, que se conservan en inglés, esta versión registra otras particularidades que no se habían considerado en las traducciones previas. Si bien nuevamente se privilegia el dominio del tango con algunos citados en versiones anteriores ("Malena", Homero Manzi, 1941; "Volvió una noche”, Le Pera, 1935; y “Tal vez será su voz”, Homero Manzi, 1943), el autor incluye nuevas frases extraídas de otros materiales que permiten reconstruir un nuevo campo de referencias culturales destinadas especialmente al público norteamericano, gesto que evidencia que sin dejar de ser un escritor que gusta de los experimentos literarios se preocupa por llegar a un público amplio. En tal sentido, la traductora asegura:

El gran conocimiento de Puig sobre la cultura popular norteamericana resultó muy valioso en nuestra colaboración creativa. Después de una larga consideración decidimos traducir sólo las letras que fueran parte esencial de la trama [...]; el resto de los epígrafes serían traducidos por frases sacadas del cine de Hollywood o de los radiocomerciales argentinos (que en realidad son versiones argentinas de la publicidad norteamericana, como el epígrafe II). Usamos artefactos relacionados con el contexto original pero que le resultaban ligeramente conocidos al lector estadounidense (JILL LEVINE, 1998, p. 163).

De esos nuevos epígrafes, dos reproducen el discurso de las publicidades radiales de los años 30 y 40 en que se ambienta la novela. Una de ellas se refiere a un dentífrico y se encuentra en la segunda entrega: “As long as you can smile, / success can be yours” (1973a, p. 21). La otra pertenece a un lápiz labial y se reproduce en la quinta entrega: “For today's modern woman, personality / comes before beauty” (1973a, p. 59). El resto corresponde a citas cinematográficas que detallamos a continuación y que Puig adapta al contexto.

En primer lugar, dos anuncios comerciales para películas, uno de Red Dust (Victor Fleming, 1932) en el tercer capítulo: "She fought with the fury of a tigress / for her man! / He treated her rough-and she loved it! ” (1973a, p. 32); y otro de Cat People (Jack Tourneur, 1942) en el decimoquinto: "She was one of the dreaded Cat people /-doomed to slink and prowl by night... / fearing always that a lover's kiss might / change her into a snarling, clawing killer!" (1973a, p. 201). En segundo lugar, tres frases promocionales de las películas Northern Pursuit en la décima entrega (Raoul Walsh, 1943): “A woman's lips set the frozen north / aflame" (1973a, p. 131); The Letter (William Wilder, 1940) en la duodécima: I wish I could say I was sorry (1973a, p. 157); y Woman in the window (Fritz Lang, 1944), en la decimocuarta: "It was 
the look in her eyes that made / him think of murder" (1973a, p. 187). Por último, unas líneas de diálogo de Swan Song (El canto del cisne, Carlos Hugo Christensen, 1945) en la séptima entrega, única película argentina citada, que se traduce y adapta de su idioma original:

$\begin{array}{ll}\text { Young composer: } & \begin{array}{l}\text { (walking along the shores } \\ \text { of an Andean lake) It is strange } \\ \text { that this unbridled nature does } \\ \text { not enthrall you, why your soul } \\ \text { is the very reflection of its beauty. } \\ \text { (new in this place) What do you }\end{array} \\ \text { klamorous widow: } & \text { know my soul? } \\ \text { Young composer: } & \text { I think I'm beginning to know it. } \\ \text { Glamorous widow: } & \text { In order to know a soul you must first dominate it. }\end{array}$

(PUIG, 1973a, p. 90)

La variedad y calidad de los materiales introducidos no deben pensarse sólo en el marco de las experiencias del pop art que desde los años 60 habían minado el campo artístico local y que Puig había asimilado durante los años de su residencia en Nueva York (1963-1967) ${ }^{24}$ y materializado en sus primeros trabajos, como puede verse en La traición de Rita Hayworth (1968), en Boquitas pintadas o en The Buenos Aires Affaire (1973b). Las referencias cinematográficas también se deben a que mientras esta traducción se realizaba, Puig estaba trabajando en The Buenos Aires Affaire (1973b), novela en la que introduce largos diálogos de películas como epígrafes para cada capítulo. De hecho, el que toma de El canto del cisne (Swang Song) también se encuentra en esa obra.

Aunque ninguno de los epígrafes para Heartbreak Tango aparece en el texto fuente, dos de ellos, el primero y el decimotercero, ya habían sido introducidos en la versión en español que Puig reacomodó para la editorial Seix Barral de España (1972b). Al pie de cada cita se menciona su procedencia, la fuente y/o el autor. Al igual que en los procesos seguidos para las versiones anteriores, la traducción de citas al inglés también pasó por una cuidadosa selección de materiales. En el documento catalogado como N.B.85.1078, escribió una lista de epígrafes con referencias breves, de entre uno o dos versos, la cual se encuentra escrita en español, pero con algunas sugerencias de traducción al inglés. Esa serie posee algunas referencias que coinciden con las que irán a la traducción publicada, por ejemplo, las de la quinta, sexta y octava entregas, y confirma la intención de incorporar citas procedentes de la publicidad, los radiocomerciales, y del cine. En otra instancia, el escritor transcribió en español epígrafes muy similares a los que aparecen en el texto fuente con varias referencias de Alfredo Le Pera, por ejemplo, y una del bolero “Azul”, pero extendiendo la cantidad de versos (N.B.86.1082-1083). 
Luego, una vez pasados a máquina en español (N.B.86.1082-85), incluyó otros tangos, algunos de los cuales no pasarán a la publicación, como "Te lloran mis ojos” de Homero Manzi, "Como abrazado a un rencor" de Antonio Miguel Podestá.

Una mención final merece el subtítulo, A Serial, que conserva en la traducción la referencia al folletín. Como en los casos anteriores, el aparato paratextual da cuenta de este aspecto en una de las solapas donde se lee: Manuel Puig conceived the novel as a lighthearted parody of a romance magazine serial of the forties. Whatever his intention, he has satisfied a universal hunger for believable romantic fiction.

\section{Los casos analizados y reflexiones finales}

Un cuadro comparativo que presenta un ejemplo de los cambios introducidos en el aparato paratextual de las ediciones estudiadas puede ser útil para sintetizar las ideas expuestas y exponer cómo los materiales se ajustan al horizonte de cada texto de la cultura receptora. A continuación se cotejan los epígrafes correspondientes al segundo capítulo:

\begin{tabular}{|c|c|c|c|}
\hline Argentina & Italia & Francia & Estados Unidos \\
\hline $\begin{array}{l}\text { "Charlemos, la tarde es } \\
\text { triste..." } \\
\text { Luis Rubistein }\end{array}$ & $\begin{array}{l}\text { Fue su amor de un día } \\
\text { toda mi fortuna... } \\
\text { (dal tango "Amargura") }\end{array}$ & $\begin{array}{l}\text { Chéri, } \\
\text { la mer où s'est miré mon } \\
\text { cœur } \\
\text { pourrait dire à son tour } \\
\text { ô combien l'amour m'a } \\
\text { coûté de pleurs... } \\
\text { ("Perfidie", boléro) }\end{array}$ & $\begin{array}{l}\text { As long as you can smile, } \\
\text { success can be yours. } \\
\text { (radio commercial for } \\
\text { toothpaste, Buenos Aires, } \\
\text { 1947) }\end{array}$ \\
\hline
\end{tabular}

Como se puede ver, se presentan citas diferenciadas en función de nuevos espacios de recepción y de un diálogo con interlocutores particulares. Para Francia se elige un bolero popular; para Estados Unidos una publicidad de dentífrico; para Argentina e Italia, tangos especialmente seleccionados, de modo semejante a lo que ocurre si comparamos el resto de los epígrafes. Lo que prima en cada uno de ellos es el reconocimiento de una atmósfera particular que remite a un tiempo pasado, el del tango y el bolero, o el de la publicidad y el cine de los años 30 y 40, épocas que se representan en la novela. De todos modos, aunque el epígrafe varíe, se produce algún tipo de relación entre la cita y el texto que preludia, con lo cual se cumple la idea de que además de remitir al exterior del texto, los epígrafes apuntan a su interior (GENETTE, 2001). Por ejemplo, si en el texto fuente la referencia se establece debido a que en la segunda entrega el personaje de Nené se contacta con Leonor por medio de las cartas para charlar sobre la muerte de Juan Carlos, el epígrafe alude justamente a esa relación comunicativa. 
Por su parte, la cita de la versión italiana instaura el vínculo a través de la idea de nostalgia por el amor perdido, algo similar a lo que ocurre con la del bolero en la versión francesa, que además está adaptada a la enunciación de una voz femenina que se dirige a su amado mediante la forma del masculino chéri. Otro aspecto, con cierto sesgo de humor irónico, señala el epígrafe de la edición para Estados Unidos. En el capítulo se sugiere que Juan Carlos ha sido el verdadero amor de Nené y que haber elegido una relación conyugal económica y socialmente conveniente no fue suficiente para olvidarlo. A pesar de que el texto presenta el fracaso de su matrimonio, el comercial que sirve de epígrafe indica irónicamente que mientras se lleve una sonrisa, el éxito estará asegurado.

Para concluir, desde el punto de vista de la colaboración del autor en todas estas traducciones, el análisis nos permite enunciar las siguientes reflexiones y observaciones.

En tanto autor y colaborador de las traducciones de su propia novela, el rol de Puig puede pensarse como el de un autotraductor (re)creador (OUSTINOFF, 2001) capaz de adoptar y adaptar todas las fórmulas y herramientas posibles que supone el texto traducido en función de llegar a potenciales lectores y nuevos espacios de circulación de la obra de la manera más efectiva. Más aún, Puig parece exceder por momentos el ejercicio de la autotraducción y se maneja con todas las libertades atribuibles a un adaptador, fronteras y líneas difusas en las que a fin de cuentas podemos considerar su intervención en este campo donde lo vemos, por ejemplo, reapropiarse de textos en la lengua de las culturas de destino y adaptarlos al contexto de la versión traducida, o poner a prueba otras posibilidades como expandir citas o abreviarlas según las condiciones de los espacios de recepción. Asimismo, su intervención se vincula con cierta preocupación por controlar de alguna manera el texto que habrá de ponerse en los distintos entornos sociales y culturales y se acopla a su inquietud por establecer un plan razonado que supone el ejercicio de la escritura, la lectura, la reescritura, la corrección, la relectura de manera minuciosa (RODAS, 2015). Esto demuestra complementariamente que más allá de ser un autor vinculado a la cultura del cine, como es bien sabido, se trata de un escritor que amplía sus horizontes en la apropiación y uso efectivo de todos los recursos disponibles.

En esta tarea vemos también cómo el original no es sino parte de un proceso en elaboración que supone un diálogo continuo y dinámico con las versiones traducidas y señala la fluidez de la escritura. Esto ocurre ya que el autor, en tanto mediador cultural (MERCURI, 2009; CARBONELL CORTÉS, 1997), además de privilegiar el contacto con el universo enciclopédico de sus potenciales lectores y seleccionar materiales capaces de ser reconocidos por este nuevo público, se esfuerza por conservar la identidad que las conecta con un elemento 
cultural representativo de la cultura de partida como lo es el tango. Esto es fundamental en la definición del espacio paratextual de Boquitas pintadas. Folletín y constituye uno de los lugares claves de la novela donde el texto sale de sí y se pone en relación con los mundos culturales de los diferentes países al tiempo que pone al descubierto sus diferencias y la definición de un público potencialmente distinto.

Los elementos paratextuales también superan su condición de elemento marginal y juegan un rol central en la dinámica relación del texto y su contexto (SPOTURNO, 2011, p. 156). En los títulos de las distintas traducciones vemos un gran esfuerzo por poner en movimiento la dinámica entre el texto fuente y la referencia al tango a través de nuevos intertextos que participan los saberes de los posibles lectores. La definición del subtítulo, que hace referencia al género con el que se vincula ambiguamente la novela, folletín, también se adapta de acuerdo con los contextos en los que la obra habrá de circular, fundamentalmente, donde la definición de las transgresiones al género puede funcionar sin lesionar ese juego ambiguo. Por su parte, los epígrafes ponen en contacto el texto con su interior al señalar y preludiar cada capítulo, pero también con el exterior al introducir y reponer cuestiones

86 culturales que serían de otro modo tal vez inaccesibles para el lector de la obra, a la vez que propician la difusión de elementos de la cultura de partida y la reapropiación de materiales de la cultura receptora.

Es en este último punto en el que se interesa muy particularmente Puig en lo que hace a su intervención sobre el aparato paratextual y experimenta, planea, pone a prueba, organiza y decide en función de los contextos de reapropiación que conoce por haberlos habitado. Recordemos que el autor había pasado largas estadías en Roma, París y New York (entre 1956 y 1967) antes del momento en que estas traducciones se realizaran. No desconoce entonces qué materiales o herramientas se ajustan mejor: epígrafes más extensos o materiales procedentes de otras esferas discursivas distintas a la del tango, pero vinculadas a la cultura popular, por ejemplo. Otro punto que no es ajeno a estas cuestiones se refiere a la rentabilidad que en sí mismas suponen estas traducciones realizadas en lenguas dominantes como el inglés, francés e italiano y que le permiten ampliar a sabiendas su público lector y un reconocimiento internacional (GRUTMAN, 2009b). Finalmente resta decir que queda para futuras investigaciones contrastar los resultados obtenidos para el caso analizado con otras novelas de Puig que presenten cuestiones similares de autotraducción y de adaptación y poner en sistema este ejercicio con el resto de su obra. 


\section{REFERENCIAS BIBLIOGRÁFICAS}

BENSOUSSAN, Albert. L'Argentine malade du tango. L'Année Littéraire 1972. Choix d'articles publiés par La Quinzaine Littéraire, París : La Quinzaine littéraire, p. 102-104. 1972.

CABRERA, Delfina. Los primeros guiones, esas cosas muy extrañas. En: Las lenguas vivas: zonas de exilio y traducción en Manuel Puig. Bs. As.: Prometeo, 2016. p. 29-60.

CARBONELL CORTÉS, Ovidio. Del "conocimiento del mundo" al discurso ideológico: El papel del traductor como mediador entre culturas. En: MORILLAS, Esther; PEÑA, Salvador (eds.). El papel del traductor. Sal amanca: Ediciones Colegio de España, 1997. p. 59-74.

FIGLIOLA, Alejandra; YOEL, Gerardo. Entramados periféricos de Manuel Puig. En: En fiebre de geometría. Puig, Saer y Mercado entre literatura y cine. Buenos Aires: Imago Mundi, 2012. p. 21-60.

FITCH, Brian. L'intra-intertextualité interlinguistique de Beckett : la problématique de la traduction de soi. Texte, n.2, p. 85-100, 1983.

GENETTE, Gérard. Umbrales. Traducido por: Susana Lage. México D.F: Siglo XXI, 2001 (1987).

GRUTMAN, Rainier. Self-Translation. En: Routledge Encyclopedia of Translation. 2nd edition. BAKER, Mona; SALDANHA, Gabriela (Eds.). Londres y Nueva York: Routledge, 2009a (1998). p. 257-269.

GRUTMAN, Rainier. La autotraducción en la galaxia de las lenguas. Quaderns: revista de traducció, n.16, p. 123-134, 2009b.

HANNA, Blake. Samuel Beckett traducteur de lui-même. Meta. Journal des TraducteusTranslators' Journal, Montreal, 4, 17, p. 220-24, 1972.

JILL LEVINE, Suzanne. Entre dos culturas: de "Boquitas pintadas" a "Heartbreak tango". En: Escriba subversiva: una poética de la traducción. México, D.F: Fondo de Cultura Económica, 1998. p. 158-171.

MERCURI, Valentina. Autotraducción, libertad de autor y mediación cultural: El caso del italiano Carlo Coccioli. Quaderns. Revista de traducció, n.16, p. 135-142, 2009.

MOLINA ROMERO, María del Carmen. De L'Aveuglon a Marruecos: una lectura a contrapelo de Agustín Gómez Arcos. Espéculo. Revista de estudios literarios, n.23, mar.-jun., 2003. Disponible en: <https://webs.ucm.es/info/especulo/numero23/cmolina.html>. Último acceso: 08 jul. 2018.

OUSTINOFF, Michaël. Bilinguisme d'écriture et auto-traduction. Julien Green, Samuel Beckett, Vladimir Nabokov. París: L'Harmattan, 2001.

PÁEZ, Roxana. Manuel Puig. Del pop a la extrañeza. Buenos Aires: Almagesto, 1995.

PAPELES son papeles. Confirmado, año VI, n.288, 23-24 de diciembre, p. 44, 1970. 
PONIATOWSKA, Elena. El tema fundamental de la obra de Manuel Puig es la relación entre autoritarios y sometidos. III Parte: Entrevista a Manuel Puig. Excélsior, México D.F., 24 de oct., p. 20, 1974.

PUIG, Manuel. Colección Manuel Puig. Arcas. GOLDCHLUK, Graciela: Organización, clasificación y comentario. Disponible en: $<$ http://arcas.fahce.unlp.edu.ar/arcas/portada/colecciones/manuel-puig >. Último acceso: 08 jul. 2018.

PUIG, Manuel. Boquitas pintadas. Folletín. Buenos Aires: Sudamericana, 1969.

PUIG, Manuel. Boquinhas Pintadas. Folhetim. Traducido por: Joel Silveira. Río de Janeiro: Sabiá, 1970.

PUIG, Manuel. Una frase, un rigo appena. Romanzo d'appendice. Traducido por: Enrico Cicogna. Milán: Feltrinelli, 1971.

PUIG, Manuel. Le plus beau tango du monde. Traducido por : Laure Guille-Battaillon. París: Denoël, 1972a.

PUIG, Manuel. Boquitas pintadas. Colección Nueva Narrativa Hispánica. Barcelona: Seix Barral, 1972b.

PUIG, MANUEL. MANUEL a casa, Gardel y leer a la Sorbona. En: Puig por Puig. Imágenes de un escritor. ROMERO, Julia (comp.). Madrid: Iberoamericana-Vervuert, 2006, p. 34-38. (Se publicó originalmente en Panorama, mayo de 1970).

PUIG, Manuel. Heartbreak Tango. A Serial. Traducido por: Suzanne Jill Levine. Nueva York: Dutton, 1973a.

PUIG, Manuel. The Buenos Aires Affaire. Novela policial. Buenos Aires: Sudamericana, $1973 b$.

RECUENCO PEÑALVER, María. Más allá de la traducción: la autotraducción. Trans. Revista de traductología, n.15, p. 193-208, 2011.

RODAS, Giselle. Boquitas pintadas. Folletín: un recorrido por las publicaciones de la novela en Argentina y España. Actas del II Congreso Internacional Cuestiones Críticas. 28-30 oct. 2009. Facultad de Humanidades y Artes, Universidad Nacional de Rosario, 2010. Disponible en: <http://www.celarg.org/int/arch_publi/rodas.pdf>. Último acceso: 08 jul. 2018.

RODAS, Giselle Carolina. Edición crítico-genética de Boquitas pintadas. Folletín (1969), de Manuel Puig. Tesis doctoral defendida el 11 de junio de 2015. Facultad de Humanidades y Ciencias de la Educación, UNLP, La Plata, Buenos Aires. 2015.

SPERANZA, Graciela. Manuel Puig. Después del fin de la literatura. Buenos Aires: Norma, 2003 (2000). 
SPOTURNO, María Laura. En la frontera del decir: los epígrafes en la narrativa de Sandra Cisneros. Estudios Filológicos, Universidad Austral de Chile. Valdivia, Chile, n.47, jun., p. 149-167, 2011.

SPOTURNO, María Laura. Decir en la lengua del otro, traducir a la propia lengua. Un estudio de las memorias de Esmeralda Santiago. Estudios de Traducción, v.4, p. 61-67, 2014.

\footnotetext{
${ }^{1}$ Giselle Carolina RODAS - Doctora en Letras por la Universidad Nacional de La Plata. Se desempeña como docente en las cátedras de Literatura Española III en la Facultad de Ciencias Sociales de la Universidad Nacional de Lomas de Zamora y en Panorama de la Literatura I de la Universidad del Cine. Participa en diversos proyectos de investigación siendo sus ejes de trabajo los archivos literarios, la crítica genética y la edición de textos. Universidad de Lomas de Zamora. Universidad del Cine. Buenos Aires, Argentina.
}

ORCID: https://orcid.org/0000-0003-3303-2538

Email: rodasgisellec@yahoo.com.ar

Sitio académico: http://www.iibicrit-conicet.gov.ar/wordpress/quienes-somos/miembros/dra-giselle-rodas/

2 El material de archivo del autor puede consultarse en el sitio Arcas de la UNLP: http://arcas.fahce.unlp.edu.ar/arcas/portada/colecciones/manuel-puig. Las referencias a los documentos de génesis de Boquitas pintadas se encuentran en: http://arcas.fahce.unlp.edu.ar/greenstone3/library/collection/puig/browse/CL1\#CL1.1,CL1.1.2

${ }^{3}$ Vale aclarar que la primera traducción corresponde a una versión para Brasil titulada Boquinhas pintadas. Folhetim (1970), a cargo del periodista y escritor Joel Silveira para la editorial Sabiá. Debido a que el aparato paratextual no posee diferencias sustanciales con respecto al texto fuente y no se guardan borradores en el archivo del escritor, que den cuenta de su participación en este trabajo, hemos decidido no integrar a nuestro corpus de análisis esta versión.

${ }^{4}$ Sobre Puig como autotraductor de sus primeros guiones para cine, puede verse: CABRERA, Delfina. Los primeros guiones, esas cosas muy extrañas. Las lenguas vivas: zonas de exilio y traducción en Manuel Puig. Bs. As.: Prometeo, 2016, p. 29-60. Recomendamos el mismo libro para cuestiones de traducción en Puig en general.

${ }^{5}$ Para Horacio Salas: “Le Pera contribuyó a apuntalar la nueva imagen internacional de Gardel. Le escribió letras sin lunfardismos, que se adosaban de manera precisa a las melodías que creaba el cantor. El objetivo era trabajar en un castellano despojado de matices locales, que pudiera ser comprendido en todos los países hispanohablantes, dentro de un marco sentimental donde Buenos Aires sólo apareciera como una referencia de lejanía, como el sitio del que alguna vez se había partido. [...] Sin embargo, sus letras nunca dejaron de tener un sabor argentino" (1986, p. 165).

${ }^{6}$ Según María Recuenco Peñalver (2011,p. 194), frente a la opinión generalizada, la autotraducción es una práctica de larga tradición desde la Edad Media. En la época moderna los casos de autores que se traducen a sí mismos forman un conjunto amplio, entre los que despuntan Vladimir Nabokov en Estados Unidos, Gabriele D'Annuzio en Italia, Héctor Bianciotti en Argentina o José María Arguedas en Perú (2011, p. 196).

${ }^{7}$ La edición de la casa Feltrinelli se imprimió en Milán, en abril de 1971.

${ }^{8}$ Compuesto en 1936 por Enrico Frati (letra) y Giovanni Raimondo (música). En una nota que se presenta antes de la portadilla, se explicita el origen de la cita y su importancia en América Latina: Una frase, un rigo appena (nel cui titolo echeggia il testo di un celebre tango) è, dopo Cento anni di solitudine di Gabriel García Márquez, il maggior best-seller dell'America Latina (1971, p. 3).

${ }^{9}$ Transcribimos: Bocche di pinte di rosso carmigno / Bocche azzurre, violacee, nere (N.B.89.1108).

${ }^{10}$ Basta sólo mencionar como parte de la tradición del género en Italia al popular relato Le avventure di Pinocchio. Storia di un burattino de Carlo Collodi, publicado entre 1882 y 1883 o, como lo resume Angelo Morino en su artículo sobre la novela: "La precisa etichetta romanzo d'appendice non può non richiamare alla mente del lettore europeo una copiosa produzione narrativa, rica di titoli sgargianti sul tipo di I misteri delle cantine, La cieca di Sorrento, Lola Montes $e$ La sepolta viva” (1977, p. 397).

${ }^{11}$ Contextualizamos los versos de Rubistein: “¿Belgrano sesenta once? / Quisiera hablar con Renée... / ¿No vive allí?... No, no corte... / ¿Podría hablar con usted? / No cuelgue... La tarde es triste / Me siento sentimental (1940, vv. 1-5).

${ }^{12}$ Contextualizamos los versos de Rubistein: “¿Qué dice? ¿Tratar de vernos? / Sigamos con la ilusión... / Hablemos sin conocernos / corazón a corazón... / No puedo... No puedo verla... / Es doloroso, lo sé... / ¡Cómo quisiera quererla! / Soy ciego... Perdóneme. .." (1940, vv. 26-33). 
${ }^{13}$ Este bolero tuvo repercusión mundial ya que fue interpretado en la película Casablanca (1942, Michael Curtiz), en una escena donde Humphrey Bogart e Ingrid Bergman bailan en un club nocturno de París.

${ }^{14}$ La obra fue publicada por Denöel dentro de la colección Les lettres nouvelles e impresa durante el segundo trimestre de 1972.

${ }^{15}$ Le plus beau tango du monde es una de las canciones de la opereta Un de la Canebière (1935) de René Sarvil, musicalizada por Vincent Scotto, y cantada por Henri Alibert.

${ }^{16}$ La canción dice: «J'ai connu d'autres tangos à la ronde, / Mais mon cœur n'oubliera pas celui-là».

${ }^{17}$ El cantante Tino Rossi (1907-1983) interpretó muchas canciones del compositor Vincent Scotto (1976-1952) quien le escribe sus primeros éxitos.

${ }_{18}$ Mariano Eusebio González y García, conocido artísticamente como Luis Mariano, fue un cantante español nacido en Irún (España) el 13 de agosto de 1914 y fallecido en París el 14 de julio de 1970. Alcanzó notoriedad como tenor y cantante de operetas y películas musicales durante los años cincuenta y sesenta.

${ }^{19}$ En la publicación se cita como “Amor”. Este bolero fue cantado por Tino Rossi en 1945.

${ }^{20} \mathrm{~J}^{\prime}$ attendrai ("Esperaré") se trata de una traducción de la canción italiana Tornerai ("Volverás") compuesta en 1933 por Nino Rastelli (letra) y Dino Olivieri (música), inspirándose en una melodía de la ópera Madame Butterfly de Puccini. La letra en francés fue escrita por Louis Poterat y cantada por Tino Rossi en 1938.

${ }^{21}$ En el tango original: "que tenés el alma inquieta".

${ }^{22}$ Basta recordar algunas de las piedras angulares del género como Les Misérables (1862) de Victor Hugo, Les Mystères de Paris (junio de 1842-octubre de 1843) de Eugène Sue, Les trois mousquetaires (marzo-julio de 1844) de Alexandre Dumas o Madame Bovary de Gustave Flaubert (1 de octubre de 1856 al 15 de diciembre del mismo año).

${ }^{23}$ Publicada en 1973 por E. P. Dutton \& Co. Inc., en New York.

${ }^{24}$ Sobre la relación entre la literatura de Puig y el pop art, Alejandra Figliola y Gerardo Yoel señalan: "Lichtenstein, famoso por sus diseños extraídos de folletines sentimentales para mujeres de los años 40 y 50 y de las historietas bélicas masculinas de la misma época, también utiliza (se apropia) de imágenes publicitarias para su obra" (2012, p. 35). Luego, prosiguen: "En forma similar, Puig se apropia de frases comerciales para reemplazar los epígrafes originales de la novela. Ambos son avisos publicitarios de la radiofonía local que él tradujo [...] Puig utiliza en la versión inglesa recursos similares a los de la generación pop: la apropiación (piratería) del material publicitario de la época" (2012, p. 35-36). Ya Roxana Páez asoció el texto con el pop art, no sólo porque es producido en su época de apogeo, sino también porque en Boquitas pintadas se leen algunos de sus gestos típicos: "incorporar algo útil, perecedero y desagradable en el marco de una obra considerada 'alta' artísticamente" (1995, p. 13). Para Páez, en Puig "esto se produce en dos niveles: -en los detalles de verismo microscópico (similar al encuadre que agranda el detalle) que, en contraste con el glamour, tienden a dibujar sutilmente un grotesco [y] en la incorporación de 'deshechos' [sic] que produce la industria cultural [...]” (1995, p. 13). Para Graciela Speranza, en Puig, "la analogía con el arte pop es elocuente; [ya que] Puig confundió su propia voz con la de sus personajes, hizo de la copia un arte y practicó nuevos usos estéticos de la cultura de masas. A la marca del sujeto individual propia de la literatura moderna opuso el 'montaje' de voces anónimas; a la originalidad, el estereotipo de las formas populares. Al modo de Warhol o de Lichtenstein, concibió un nuevo arte 'popular' que incorpora íconos, objetos, restos del entorno cotidiano de consumo masivo mediante una sutil transformación que los convierte en arte, sin perder la propiedad objetiva que los vincula a la experiencia cotidiana y sin producir por eso efectos paródicos o críticos. Superponiendo las instancias de reproducción y producción, desafió los límites de la parodia, el mero consumo y la consolación" (2003, p. 14). 